\title{
Cognitive Mechanism for Metaphor Translation
}

\author{
Fang Wang \\ School of Foreign Languages, Changchun University of Science and Technology, Changchun, China
}

\begin{abstract}
This research carries out a detailed study on the cognitive mechanism for translation of metaphors, which involves dual phases of comprehension and reproduction. Recognized as the basis of appropriate rendering, a proper comprehension of the target metaphor is highly appreciated. Moreover, there are various factors in the comprehension of metaphor, namely, the semantic discrepancy, in the discerning of sense, cultural differences, individual characteristics in image conjuring, and the role of context. On the other hand, in the phase of reproduction, due consideration shall be taken to the concern of style.
\end{abstract}

Index Terms — cognitive mechanism, metaphor, translation

\section{INTRODUCTION}

It is no exaggeration to assert wherever there is thought, there is metaphor; wherever there is language, there are metaphors. Given the cognitive qualities of metaphor as well as the nature of translation, translation of metaphors is taken as a cognition-oriented mental process, in which the human brain unravels and delivers the cognitive information of the source metaphor. Via this way, we hold that the nature of translation of metaphors is virtually a process of crosscultural delivery of cognitive information.

Whenever it comes to translation, we are using a metaphor, that is, to convey something (from one place ) to (another place), because the word “translation"comes from Latin, “trans”(穿过) and “latus"(the past participle fero, ferri, fuli) (运送).The Greek root of metaphor parallels with the root of translation: “meta” means “穿过”, “phor” means “运送”. In fact "phor" and "fer" (in "transfer") are two different kinds of translation of one word.

Metaphor in one form or another is completely essential to the way language systems develop over time and are structured, as well as to the way human beings consolidate and extend their ideas about themselves, their knowledge and their relationships about the world. On Martinet's model we may regard words as the first articulation of meaning, and since all symbols are metaphors or metonyms replacing their objects, all words are therefore metaphorical.

However, as translators we know that words in context are neither things nor usually the same symbols as individual words, but components of a larger symbol which spans a collocation, a clause or a sentence, and is a different symbol than that of an isolated word, This is the second articulation of meaning and to this extent language itself is a metaphorical web. So language, in nature, is metaphorical. Translation is transfer of one language to another language and the process of translation is a thinking process. The translation process is also metaphorical process. Therefore, metaphor translation is really a challenging task.

\section{LITERATURE REVIEW}

\section{The First Phase of Metaphor Translation: Comprehension}

To probe the approaches to metaphor translation, we need two processes: one is the comprehension of metaphors, the other is reproduction of metaphors from one language to another language.

The study of the comprehension process of metaphor has been a major topic in theories of metaphor. It has been generally taken that the semantic, contextual and cultural information play an Important role in the comprehension of metaphorical expressions. Nevertheless, it remains to be viewed as to what type of information and how much amount of it is needed for the right understanding of a novel metaphor. The other important issues involved include the identification of a metaphorical expression and the working out of metaphorical meanings. "Metaphorical word functions only when it is contrasted with other non-metaphorical words; the self-contradiction of literal interpretation is necessary for the unfolding of metaphorical interpretation." (Beardsley, 1958, p.20)

Identifying chunks of language as metaphors is not always easy because we do not usually notice them as metaphors. Once they are identified, they are in the source language. The comprehension phase leads to choosing one equivalent expression from the possible ways of expressing the target language and target culture. Interpretation takes advantage of the comprehension step, and lies in relating the metaphoric expression to its conceptual metaphor.

A metaphor can be identified in the following ways: one is by the clear signal of a metaphor: "to put it metaphorically" "speaking metaphorically" or, "in a metaphorical sense" and so on. Secondly, through the anomaly both in semantics and in pragmatics with the assumption that the speaker is making sense. That is to say, the two (or more) referents of the metaphor should be logically anomalous either semantically or pragmatically. The referents of a metaphor usually belong to two different semantic domains. Metaphorical transfers of meaning are transfers from the 
field of the vehicle to the field of the tenor of the relations of affinity and opposition that the vehicle terms bear to other terms in its field. More precisely, what is transferred are the relations which pertain within one semantic field to a second, distinct content domain in metaphor.

For instance, we say a basketball player that her playing is "hot" in a game, "hot" is the vehicle, and its semantic field is the field of temperature terms; the domain of the tenor is athletics. Antonyms in the temperature field, hot and cold are considered; we can describe a hot player as one who plays well and scores, when they are changed to sports, while a cold player does not. The antonym of the pair is remained. Furthermore, if a player scores only just so so, we can say "he was lukewarm in the third quarter." Because "hot" and "old" are not absolute but relative antonyms, even on the extremes we can capture all sorts of performances, for example: "Her performance on the court today is sizzling". In this way metaphor can, through a transposition of relations, structure yet unstructured conceptual domain or record another semantic field, thus changing sometimes, sometimes forever, our ways of understanding our world.

The third is to detect the violation of cooperative maxims. Grice(1965) develops his cooperative principle into nine maxims which are classified into four categories:

"1.Maxim of quantity

Make your contribution as informative as required.

Do not make your contribution more informative than is required.

2.Maxim of Quality

Do not say what you believe to be false.

Do not say that for which you lack adequate evidence.

3.Maxim of relation

Be relevant

4.Maxim of Manner

Avoid obscurity of expression

Avoid ambiguity

Be brief

Be orderly" (Grice, 1965, p.37)

It is usually agreed that metaphorical statements often violate the maxim of relevance and the maxim of quality. Let's look at a few examples:

"I am as hungry for them as for food, I am thirsty for them, and my thirst is overwhelming. Your words are my food, your breath my wine. You are everything to me."

("100 World's Great Letters" Sarah Bernhardt to Victorian Sardon).

These sentences break the maxim of quality and the maxim of relevance. Since these words appear in a love letter, so the context gives the hint that we cannot understand them literally.

Another example:

In this business, we are the sheep and you are the wolves. We will preserve our character, and hope you will change yours. ("100 World's Great Letters" Joseph Priestley to His neighbors of Birmingham)

We will infer through the connotational content of "sheep" and "wolves" which might be "good, considerate people" and "fierce and violent neighbors".

\section{The Second Phase of Metaphor Translation: Reproduction}

If we take metaphor translation as a process of decipherment, we have finished the first step. As a translator, he is both a receiver and a sender. He is the receiver of the message of the source, ie, he is decoding message of the source: he is the sender of the message of the source, ie, he is encoding message from the system of source linguistic symbols to the system of target linguistic symbols. In encoding the metaphors into the target linguistic symbols we must pay due attention to the cultural divergences in order not to make misunderstanding and appropriate style to achieve the same effect that the source text brings upon the native readers.

\section{A. Avoidance of Sharp Cultural Color}

Analyzing from macroscopic angle, all the human being cultures have general characteristics. But taking a microcosmic viewpoint, we can find all the national cultures are individual. This individuality exists widely from the very beginning to the very end of the whole national culture, so it is not surprising we find more metaphors in Chinese and English that do not embody the "formal likeness", "meaning likeness" and "spiritual likeness" simultaneously. A lot of such metaphors are similar in meaning, but not in form. For really successful reproduction, biculturalism is quite more important than bilingualism. As words have only meaning in cultures where they function.

How to encode the cultural image into the target linguistic symbols has always puzzled translators. In essence, it is the contradiction between the form and content of the source material. Of course, in reproducing the image of those metaphors which embody the strong cultural color, we'd better use the image of the target language that is familiar to the readers. As the communication between China and English becomes more frequent, we may directly reproduce the vehicle into the target language. For example, “He is an old screw.” We may reproduce the sentence into“他吝啬得像 
一枚起不动的螺丝钉”. Such translation conveys the information from the source sentence, and also introduces some new image into the target language. Hence, it enriches our cultural images.

\section{B. Awareness of Appropriate Style}

Not only must translating cover the entire range of subject matter, but it is required to do so in an equally wide range of styles: easy/difficult, serious/lighthearted, fresh/dull, colorful/drab, exciting/boring. These stylistic differences are the basis for much of the text's associative meanings, which are often far more important than the designative meaning. A text which is stylistically attractive can be more challenging and personally rewarding to the translator. Style is the basic characteristic of every piece of writing, the outcome of the writer's his emotions and personality, and without revealing no single paragraph can be put together to some degree the nature of its author. The author's style determines his choice of a word, and, as has been seen, the translator is also compelled to make a choice of a word in the target language.

However, it is quite impossible to stand for some of the stylistic subtleties of the original.

\section{Solving Semantic Discrepancy}

In a metaphor, there might be a combination of similarity and dissimilarity between the two referents, that is to say, they must be both quite similar and dissimilar. It does not mean that similarity is metaphor. It is only a condition of metaphor, or metaphor is usually based on similarity.

One of the design features of metaphor is its semantic anomaly. A metaphor constitutes the violation of semantic selectional restrictions, because the tenor and the vehicle belong to two different domains or categories of experiences. We call the difference between the tenor and vehicle the "distance" or "semantic impertinence". Which has to be bridged to interpret the metaphorical meaning of the metaphor. The key concept in this "tension elimination" process is "resemblance". To better comprehend its nature in metaphorical statements, we shall have a broad view of the meaning of resemblance. In other words, we should take resemblance to mean similarities not only in physical appearances, but also in functions or other aspects.

Aristotle points out that to see sameness in what is different is to see similarity. Metaphor reveals the logical structure of the "similar" because, in the metaphorical statement, the "similar" is perceived despite difference, in spite of contradiction. Therefore, resemblance, is the logical category corresponding to the predicative operation in which "approximation" meets the resistance of "being distant". In other words, metaphor shows the work of resemblance since the literal contradiction keeps difference within the metaphor statement; "same" and "different" are not just mixed together, they also remain opposed. Enigma lives on in the heart of metaphor through this specific trait., "the same" operates in spite of "the difference" in metaphor.

When we say that metaphor succeeds through similarity or resemblance, we do not merely mean the resemblance that preexist between the tenor and the vehicle, but also imagined or created similarities through the juxtaposition of the two seemingly dissimilar subjects and their respective domains. Similarity-creating metaphors take up a major portion of the metaphors we usually encounter, and they are cognitively more valuable than metaphors that are based on preexisting similarities.

The production and interpretation of a metaphor are always based on human psychology, especially the two capabilities of human psychology: association and imagination. Association is a conditioned reflex. For example, we associate winter with coldness, sun with sunlight and so on. Generally speaking, concrete and familiar things are easy to be associated with, and, therefore, they are often used to describe or expose the abstract and profound things to make them easier to understand.

There is the so-called similarity-association, which refers to association of similarities in attributes or relations. This is very important for both the invention and interpretation of a metaphor. There is attribute similarity of viciousness in "The man is a wolf." and relational similarity of "father and offspring of his country." In the latter case, the relation between Washington and his country is similar to that between father and offspring. Such similarities are very important for metaphors, since metaphors are based on analogy.

Therefore, to find the preexisting or existed similarities is the key to solve semantic discrepancy. Whether a metaphor is appropriate or not depends on whether there are similarities between the involved discrete referents. The association of similarities serves as a bridge between the discrete referents.

"Let us consider more loosely what happens in the mind when we put together in a sudden and striking fashion two things belonging to very different orders of experience. The most important happenings in addition to a general confused reverberation and strain--- are the mind's efforts to connect them. The mind is a connecting organ and it can connect any two things in an infinitely large number of different ways. Which of these it chooses is settled by reference to some larger whole or aim, and though we may not discover its aim, the mind is never aimless. In all interpretation we are filling in connections" (Richards, 1936, p.124)

In trying to interpret a metaphorical statement, the hearer or reader usually tries to look for the salient aspect of the meaning or the image of the vehicle and transfer them to the tenor. Hester (1967) explained the metaphorical meaning as "seeing as". The factor of "seeing as" is exposed through reading, to the extent that this is "the mode in which such imagery is realized. (Hester, 1967, p.21) The "seeing as" is the positive link between tenor and vehicle. To explicate a metaphor is to list all the appropriate senses in which the vehicle is "seeing as" the tenor. The "seeing as" is the intuitive 
relationship that makes the image and sense hold together. Often there are three major aspects of features the hearer or reader needs to "see" in a vehicle:

Physical characteristics

For example, "Sally is a block of ice." The physical characteristics of "ice" can be described as "cold". The equation of "Sally" with "ice" evokes the physical characteristics of "ice" and the imagery is vivid enough for the success of the metaphor. So the semantic discrepancy is solved. The sentence can be understood as "Sally is unemotional".

Behavioral characteristics

For example, "The woman's tears are the leaves of the autumn, keep falling." The equivalence of "tears" with "leaves" obviously is based on the behavioral characteristics of both.

Functional characteristics

For example, "Eyes are tongues of animals that cannot speak." We see things with eyes and we speak with tongues. But animals can only see with eyes, and cannot speak with tongues. Since there exists a metaphor, this metaphor must be based on the similarity of function between the two subjects, which is "ability to speak".

Some metaphors may, of course, take several aspects of characteristics of the vehicle as their ground.

\section{Addressing Cultural Divergences}

To those who are interested in translation, especially in literature translation, an important topic for study is the cultural value of language. In addition, what is culture? "Culture consists of all the shared product of human society" (Robertson, 1981, p.105) This means culture includes not only material things such as cities, organizations, and schools, but also nonmaterial things such as ideas, customs, family patterns, and languages. In a word, culture refers to the entire way of life of a society. What's more, culture is like an iceberg with a big part of its real substance hidden in the sea. "Culture hides much more than it reveals, and strangely enough, what it hides, it hides most effectively from its own participants". (Kaplan, 1989, p.78) Language plays an important role in it and is a part of culture. Some social scientists think it the keystone of culture. On the other hand, language is affected and shaped by culture. Culture is reflected. As the word is the most lively element of a language.

All human beings speech contains arbitrarily selected but highly conventionalized signals; meaning can never be separated from expressive form. Even the most purely ostensive, obviously neutral terms are embedded in linguistic particularity, in an intricate mold of cultural-historical habit. Since language is metaphorical, and words have meanings in terms of the cultures where they function, the comprehension of metaphors is closely connected with culture.

When defining the same object, languages in different countries are different in category, extension, and intension etc., which reflects cultural difference. Things or concepts that are represented by one or perhaps two terms in one language, but by many more terms in the other language; that is, finer distinctions exist in the other language. In the broad sense, language is the symbolic representation of a person, and it comprises their cultural and historical backgrounds or their ways of thinking and living. Language and its cultural influence are exemplified in the SapirWhorf hypothesis, which in basic states that language is a guide to "social reality". The hypothesis implies that language is not only a way of reporting experience but also it is a way of defining experience. Terms have more or less the same basic meaning, but have secondary meanings that may differ from each other.

We have mentioned in the previous paragraphs that the words people speak refer to shared experience. They express ideas, or facts that are communicable because they refer to all kinds of knowledge about the world that other people share. Also words reflect the authors' beliefs and attitude, their points of view, which are also those of others. In both cases, language expresses cultural reality. When you are communicating with someone from your own culture, the process of using words to represent your experiences is much easier because within a culture people share many similar experiences. When communication is among people from different cultures, the process is more complicated.

It is important to be familiar with culture background of the words in linguistic translation. Take "A Dream of Red Mansion". In this famous work, there is such occasion: Wang Xifeng and Baoyu hold a funeral procession, and Wang said to Baoyu: “别学他们猴在马上.” To show Wang Xifeng's shrewish and cordial vividly, David Hawkes translate this sentence into "You don't want to go clomping around the countryside like apes on horseback with those men", which reappear Wang Xifeng's tone lively.

Each country has its own culture, and each culture has its own unique characteristics. These unique characteristics reflected in the languages, therefore, result in barriers of translation, especially the translation of metaphors. One of the important features of metaphor is the imagery which is evoked through a word that describes an animate or a familiar subject. The images usually embody many unique cultural elements. It is obvious that people often connect certain qualities with some objects or creatures. Certain emotions or reactions are aroused, as there is little or no scientific base for such association. The qualities that are connected, or the emotions that are aroused, are not the same with different people.

Different nationalities exist in different living environment and different cultural tradition, so specific cultural images are constructed. These images are used to create metaphors. The most-favored animals should be the phoenix and the dragon in Chinese culture. "Dragon" has its cultural image both in English and Chinese. In our culture, dragon is the symbol of emperor, and the phoenix for the empress. In Chinese legends, "dragon" is believed to control the forces of nature, come and go unnoticed. People show both respect and fear to dragons. For this reason, "dragon" also symbolizes 
stateliness and might. So many Chinese words containing "dragon" are associated with nobleness and sacredness, such as “真龙天子”, “龙宫”, “龙颜”, “龙袍”, “龙床”, “望子成龙”, etc.

However, to native English speakers, the dragon is often a fierce monster that destroys, a symbol of evil, so dragon is the symbol of horror and must be killed. And the phoenix is not at all the spouse of a dragon; moreover, it reminds people of rebirth and resurrection. For example, "The woman in charge of the accounts department is an absolute dragon!" In this sentence, dragon conveys the fearfulness of the woman. When we Chinese proudly say that we are the descendents of dragon, English-speaking people cannot understand Chinese pride in saying so. In the translation of metaphors, we should be aware of the divergency of the cultural image.

The English word "daffodil" is often used with the meaning of the spring or joy, (just like the "west wind"), as in Shakespeare's sonnet:

When daffodils begin to peer

With heigh, the doxy over the dale!

Why, then comes in the sweet o'the year

A deeper description of daffodils as the messenger of the spring can be found in William Wordsworth's "The Daffodils". Such an image of the daffodil being a symbol of the joyful spring time, but, is not popular in the Chinese culture. On the contrary, a lot of Chinese words with special images can not arise English-speakers any association.

The translatability of a metaphor is determined by the extent to which the cultural experience and semantic associations where it draws are common by speakers of the special target language. In order to fully and exactly understand metaphors we must keep a close eye on the cultural divergences of cultural images.

\section{E. Comprehending Individual Empiricism}

Metaphors are full of creativity. Some metaphors can be easily identified, but they are not conventional. They belong to their creators. To comprehend and translate such metaphors are more difficult than to comprehend and translate conventional metaphors. The creative metaphors don't belong to linguistic system. They may reflect the creators' psychological and cognitive process.

For example, we usually take theories as buildings. Based on this conception, we may say "His theory has a solid foundation." To comprehend this metaphor is quite easy. But if someone say "His theory has thousands of little rooms and long, windy corridors." It is difficult to understand. Although this metaphor is also based on the same conception: Theories are buildings, the creator of the metaphor emphasizes the different aspects. Such metaphor may not be invented by most people, so it actually belongs to individual rather than the linguistic system. These metaphors don't reflect certain cultural features. The creator's real purpose is to speak something vividly.

Such individual metaphors mostly appear in literary works. Because literature is art of language, the features of expression in language are of great importance, and more metaphors are created in literary works.

For example,

"1. Drive my mad thought among the universe.

Like withered leaves to quicken a new birth.

2. the trumpet of a prophecy! O Wind,

If Winter comes, can Spring be far behind?"(Ode to the West Wind)

The value of these metaphors is far greater in language, because the metaphors in literary works are more meaningful. The difficulties arise when the metaphors are so inventive. But we usually keep the metaphors in translation, to obtain the flavor of the original material.

\section{F. Seeking Clues from Context}

The contextual theory of meaning was first proposed by the English anthropologist Malinowsky and later developed by his student and successor J.R. Firth. Malinowsky and Firth distinguish two types of contexts: one is the larger social or cultural context, the other one is the smaller verbal context where a specific utterance takes place. The latter is always embedded in the former and hence determined by it.

Black pointed out that context was not only important for the comprehension of metaphor, but that in many cases, it was absolutely necessary in order to distinguish whether a phrase was literal or metaphorical in the first place.

Generally speaking, to make it easier for the hearer to comprehend a metaphor, the speaker selects a vehicle which can be understood without calling for specialized knowledge. However, to comprehend most novel or new metaphors, we need to seek clues from a variety of contextual knowledge.

1). Social context is essential for a better appreciation of this metaphor.

a. Fictional figures in classical literature

b. Historical figures or events

c. Special subject knowledge

d. Folklore or legends

e. Religions

2). Linguistic context

Linguistic context plays a key role in deciding whether a metaphor exists or not. For example, when an egg smells odorous, “臭” is not metaphor. But when we are watching a game, “臭” is used metaphorically. Another 
example: ..."At the expense of everything else, my health, my family, my fiancée he left me. She knew she had a rival." If we separate the last sentence from the context, it is not a metaphor. But after we associate the last sentence with the previous information, we know the word is used metaphorically. The tenor is "my job" and the vehicle is "a rival".

\section{SUMMARY}

A detailed study is carried out in this chapter on the mechanism of the cognitive approach to translation of metaphors, which involves dual phases of comprehension and reproduction. Both of the two phases are realized largely through introspection. Recognized as the bases of appropriate rendering, a proper comprehension of the target metaphor is highly appreciated, and there are various factors in the comprehension of metaphor, namely, the semantic discrepancy, in the discerning of sense, cultural differences, individual characteristics in image conjuring. Secondly, the phase of reproduction includes the encoding of the cognitive message from one system of linguistic symbols to another; hence due attention shall be paid to the concern of style.

\section{REFERENCES}

[1] Beardsley, M. C. (1958). Aesthetics: Problems in the Philosophy of Criticism. New York: Harcourt.

[2] Grice, H. P. (1965). Meaning. New York: Doubleday \& Co.

[3] Hester, M. B. (1967). The Meaning of Poetic Metaphor: An Analysis in The Light of Wittgenstein's Claim that Meaning is Use The Hague-Paris: Mouton.

[4] Kaplan, D. (1969). Words and Objections. Dordrecht: Reidel.

[5] Richards, I. A. (1936). The Philosophy of Rhetoric. London: Oxford University Press.

[6] Robertson, M. (1981). Lamarck Re-visited: The Debate Goes on. New scientist 90-230.

Fang Wang, MA in linguistics, earned in Jilin University, Jilin Province, China, in 2007. The major field is critical discourse analysis.

She is now the lecturer in CUST and is studying for her Ph.D. degree in Jilin University. His main published articles include Resolving Ambiguity in Familiar and Unfamiliar Casual Speech, Exploring Teaching Beliefs in Teaching EAP at Low Proficiency Levels. 